\title{
ГІДРОБІОЛОГІЯ
}

УДК [(581.4 + 581.5):581.526.323] (285.3)

doi: $10.25128 / 2078-2357.20 .3-4.10$

\author{
О. А. ДАВИДОВ, О. В. КРАВЦОВА \\ Інститут гідробіології НАН України \\ пр-т Героїв Сталінграда, 12, Київ, 04210 \\ e-mail: davydovoleg01@gmail.com
}

\section{ЕКОЛОГО-МОРФОЛОГІЧНА СТРУКТУРА МІКРОФІТОБЕНТОСУ ОЗЕРА ТЕЛЬБІН}

У мікрофітобентосі оз. Тельбін встановлено основні еколого-морфологічні групи водоростей. Виявлено, що до їхнього складу входять не тільки бентонти, а й планктонти, що осідають на дно 3 товщі води, та перифітонти, принесені токами води 3 вищої водяної рослинності або твердих субстратів. З'ясовано, що в літній період планктонти та перифітонти відіграють основну роль у формуванні видового багатства мікрофітобентосу, через що альгоугруповання представлено альгоагрегацією - нестійкою сукупністю водоростей у біотопі, що вказує на несприятливі умови існування на дні для представників резидентної альгофлори.

Ключові слова: мікрофітобентос, еколого-морфологічна структура, екологія водоростей, альгоугруповання, водойма урбанізованої території.

На сьогодні важливим завданням санітарної гідробіології $\epsilon$ дослідження зв'язку альгоугруповань мікрофітобентосу з екологічними умовами різнотипних водних об'єктів, що відрізняються факторами середовища, які відіграють визначальну роль у формуванні їхньої структури та рясності [16].

Під впливом антропогенного навантаження багато факторів змінюються, відповідно мікрофітобентос може виступати у якості надійного біоіндикатора порушення стану гідроекосистем у результаті антропогенного пресу на водні об' єкти.

Біоіндикація на основі структурних елементів мікрофітобентосу потребує глибокого аналізу причинно-наслідкових зв'язків у гідроекосистемах залежно від умов та особливостей певних типів водних об' єктів.

Для ряду водних об'єктів України (дніпровських водосховищ, понизь Дніпра, Південного Бугу та Дніпровсько-Бузького лиману, української ділянки Дунаю) детально проаналізовано еколого-морфологічну структуру мікрофітобентосу, за отриманими результатами охарактеризовано донні альгоугруповання та виділено альгоценози. Це дозволило оцінити за порушенням структури та рясності останніх ступінь погіршення екологічного стану різних ділянок досліджених водних об'єктів [15].

Дослідження еколого-морфологічної структури мікрофітобентосу озер урбанізованих територій нечисленні $[3,17]$, тому такі дослідження є актуальними.

Мета роботи полягає у встановленні еколого-морфологічних груп водоростей у мікрофітобентосі водойми урбанізованої території 3 високим відносним ступенем антропогенного впливу та визначення їх ролі у формуванні певного типу альгоугруповання. 


\section{Матеріал і методи досліджень}

Матеріалом послужили результати досліджень мікрофітобентосу оз. Тельбін, розташованого на території житлового масиву «Березняки» м. Києва, влітку 2016 р. Даний водний об’єкт є залишком заплавних водойм Лівобережжя Дніпра. Загальна площа водойми 12,4 га, довжина 0,8 км, ширина 100-160 м, глибина близько 13 м [7].

Проби мікрофітобентосу відбирали мікробентометром МБ-ТЕ (загальна площа відбору $40 \mathrm{~cm}^{2}$ ) у трьох повторностях у літоральній зоні на глибинах 0,5-2,0 м, у місцях, вільних від заростей вищої водяної рослинності, та на глибоководних ділянках - 6 м. Відбір та камеральну обробку проб проводили за загальноприйнятою методикою [5]. У роботі використовували таксономічну систему водоростей, запропоновану у зведенні «Algae of Ukraine» [10], латинські назви видів приведено відповідно до AlgaeBase [12].

Орієнтовний відносний ступінь антропогенного впливу на екосистему водного об’єкту виражали в балах, застосовуючи метод, за яким виділяються декілька найбільш очевидних антропогенних чинників (промислова чи житлова забудова, штучна зміна морфометричних характеристик, наявність транспортних шляхів, наявність автостоянок, зливовий стік 3 промислової забудови, зливовий стік із житлової забудови, рекреація, аматорське рибальство) і оцінюється наявність їх для кожної водойми з урахуванням різної інтенсивності їх впливу [6].

У мікрофітобентосі еколого-морфологічні групи виділені з урахуванням характеристик приуроченості водоростей до певних біотопів $[1,4,8,9,10,11,14,17]$.

Для встановлення параметрів відхилення відносних показників структурних компонентів мікрофітобентосу за різного ступеня антропогенного впливу використані дані досліджень еколого-морфологічної структури мікрофітобентосу оз. Міністерське [3].

\section{Результати досліджень та їх обговорення}

Проведені дослідження дозволили встановити, що орієнтовний відносний ступінь антропогенного впливу на екосистему оз. Тельбін характеризувався досить високим показником -8 балів (сума наявних чинників антропогенного впливу: промислова чи житлова забудова <<++>>, штучна зміна морфометричних характеристик <<+>>, наявність транспортних шляхів $\langle\langle+\rangle\rangle$, наявність автостоянок $\langle\langle+\rangle\rangle$, зливовий стік 3 житлової забудови $\langle<+>>$, рекреація $\langle<+>>$, аматорське рибальство $\langle<+>>$ ).

У структурі мікрофітобентосу водойми виділено 7 еколого-морфологічних груп водоростей (ЕМГ). Еколого-морфологічними групами бентонтів є ЕМГ евритопних літоральних діатомових водоростей - БЕлд, ЕМГ крупних діатомових - Бкд, ЕМГ дрібних та середніх діатомових - Бдсд, ЕМГ ниткуватих синьозелених водоростей - Б $\mathrm{b}_{\mathrm{X}}$. Планктонти представлені ЕМГ А Пл, перифітонти - ЕМГ $\mathrm{A}_{\text {Пр. }}$

У літоральній зоні відмічено ЕМГ Б Елд, ЕМГ Б Бд, ЕМГ Бдсд, ЕМГ Б НС $_{\text {, ЕМГ Б }}$, ЕМГ АПл, ЕМГ А Ар. На глибоководних ділянках загальна кількість ЕМГ була меншою та формувалась

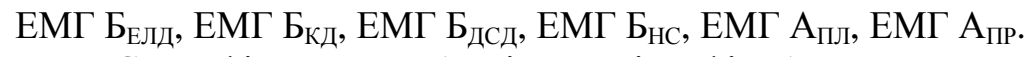

Специфічною особливістю мікрофітобентосу водойми $\epsilon$ те, що в літній період представленість автохтонних компонентів - облігатних та факультативних бентонтів у видовому багатстві - украй низька та не перевищувала $36,6 \%$.

Серед бентонтів основна роль у формуванні видового багатства мікрофітобентосу

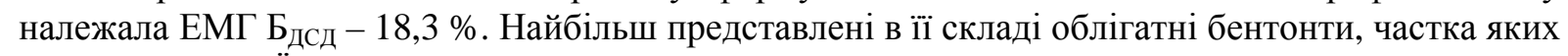
складала 82 \%. Їхніми типовими представниками були: Placoneis dicephala (Ehrenb.) Meresch., Hippodonta capitata (Ehrenb.) Lange-Bert., Metz. and Witk., Navicula cari Ehrenb., Navicula reinhardtii (Grun.) Grun., Amphora veneta Kütz., Pinnularia gibba (Ehrenb.) Ehrenb., Aneumastus tusculus (Ehrenb.) D.G. Mann and Stickle, Caloneis silicula (Ehrenb.) Cleve. Факультативні бентонти представлені лише двома видами: Cymbella cymbiformis C. Agardh та N. cryptocephala Kütz.

Еколого-морфологічна група Бкд, яка зазвичай відіграє важливу діагностичну роль у альгоценозах мікрофітобентосу в різнотипних водних об' єктах України, в оз. Тельбін кількісно не вирізнялась. Її частка у видовому багатстві не перевищувала 8,3\%. Найбільш розповсюджені у іï складі ЕМГ БКд облігатні бентонти (до 80 \%): Pinnularia viridis (Nitzsch) 
Ehrenb., P. major (Kütz.) Rabenh., Stauroneis anceps Ehrenb., Stauroneis phoenicenteron (Nitzsch.) Ehrenb. Факультативні бентонти представлені лише C. lanceolata (C. Agardh) Kirchner.

Евритопні літоральні діатомові (ЕМГ БЕлд) представлені виключно факультативними бентонтами: Pseudostaurosira brevistriata (Grun.) D. M. Williams and Round та Ulnaria ulna (Nitzsch.) Compère. Їхня частка у видовому багатстві мікрофітобентосу не перевищувала 3,3\%.

Еколого-морфологічна група $5_{\mathrm{HC}}-$ бентосні форми ниткуватих синьозелених водоростей, частка яких у видовому багатстві мікрофітобентосу складала 5,0 \%. Основними компонентами ЕМГ Бнс були облігатні бентонти, серед яких найбільш часто в літоральній зоні траплялися Oscillatoria tenuis C. Agardh ex Gomont, O. amphibia C. Agardh ex Gomont, а на глибоководних ділянках - O. исrainica Vladim.

Харові водорості (ЕМГ БХ $)$ представлені десмідієвими 3 роду Cosmarium, які зазвичай приурочені до місць 3 ознаками заболочення. Їхня роль у формуванні видового багатства мікрофітобентосу була найменшою - $1,7 \%$.

Серед усіх ЕМГ водоростей, які реєструвались у мікрофітобентосі оз. Тельбін, найбільш вагома роль у формуванні видового багатства належала планктонтам $\left(\right.$ ЕМГ $\left.\mathrm{A}_{\text {пл }}\right)-36,7 \%$. У переважній більшості це види, що викликають «цвітіння» води: синьозелені ниткуваті водорості, планктонні діатомові, зелені, що за певних умов з різною інтенсивністю осідали 3 товщі води на дно. На дні як літоральної, так і глибоководної зон, систематично реєструвалися Aphanizomenon flosaquae Ralfs ex Born. and Flah., Dolichospermum flosaquae (Bréb. ex Born. \& Flah.) P. Wacklin, L. Hoffmann and J. Komárek, D. scheremetieviae (Elenkin) Wacklin, L. Hoffm. \& Komárek, O planctonica Wolosz., U. acus (Kütz.) Aboal, Stephanodiscus hantzschii Grun., Nitzschia acicularis (Kütz.) W.Sm., численні види родів Scenedesmus та Desmodesmus. Дослідження фітопланктону оз. Тельбін також засвідчили, що основу видового складу фітопланктону оз. Тельбін становлять представники відділу Cyanoprokaryota [13], а такі види, як D. flosaquae (Bréb. ex Born. \& Flah.) P. Wacklin, L. Hoffmann \& J. Komárek, A. flosaquae Ralfs ex Born. and Flah., є домінантами за чисельністю [2].

Особливої уваги заслуговує присутність у складі ЕМГ А Пл по всьому вертикальному профілю відкосу видів роду Trachelomonas (T. volvocina (Ehrenb.) Ehrenb., T. hispida var. coronata Lemm.), Strombomonas (Strombomonas longicauda (Swir.) Defl.) та Phacus (Phacus caudatus Hübner та $P h . s p$.), що може вказувати на органічне забруднення водойми.

Перифітонти (ЕМГ $\mathrm{A}_{\text {ПР }}$ ) - найбільш багаточисельна після планктонтів ЕМГ у мікрофітобентосі, формували 26,7 \% видового багатства. Представлена переважно діатомовими водоростями: видами родів Cocconeis (Cocconeis placentula var. euglypta (Ehrenb.) Grun.), Gomphonema (G. augur Ehrenb., G. angustum C. Agardh, G. truncatum Ehrenb.), Cymbella (C. cistula (Ehrenb.) O. Kirchner), Encyonema (E. paradoxum Kütz., E. silesiacum (Bleisch) D.G. Mann), Gomphoneis (G. olivaceum (Hust.) Aysel), Epithemia Küting (E. argus (Ehrenb.) Kütz., E. sorex Kütz.), Planothidium (Pl. delicatulum (Kütz.) Round \& Bukht. та Pl. rostratum (Østrup) Lange-Bert.), Rhoicosphenia abbreviata (C. Agardh) Lange-Bert. та ін. Із зелених водоростей у літоральній зоні траплялися фрагменти ниток Oedogonium sp.

Таким чином, дослідження еколого-морфологічної структури мікрофітобентосу оз. Тельбін дозволили встановити, що в літній період основна роль у формуванні видового багатства альгоугруповання на дні водойми належала планктонтам (ЕМГ А пл) та перифітонтам (ЕМГ АПР) (сукупна частка яких складала 63,4 \%). Серед бентонтів найбільш представлена ЕМГ БЕлд та ЕМГ Бкд, роль інших ЕМГ несуттєва.

Отримані дані дали змогу провести порівняльний аналіз досліджених показників структури мікрофітобентосу у водоймах із різним відносним ступенем антропогенного впливу. Для порівняння залучені дані по оз. Міністерське (оз. Редькіне), яке знаходиться у рекреаційній зоні на околиці Києва [3]. Відносний ступінь антропогенного впливу на його екосистему значно нижчий, ніж на оз. Тельбін, та не перевищує 3 бали (сума наявних чинників антропогенного впливу: наявність транспортних шляхів $\langle<+\rangle>$, рекреація $\langle<+>>$, аматорське рибальство $<<+>>)$ [6].

Встановлено, що у цих водоймах відносні показники структури донних угруповань водоростей суттєво відрізняються на рівні майже всіх ЕМГ. Зокрема, у оз. Тельбін частка ЕМГ 


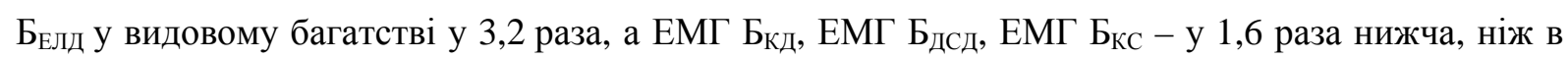
оз. Міністерське; натомість частка перифітонтів (ЕМГ $\left.\mathrm{A}_{\Pi \mathrm{P}}\right)$ та планктонтів $($ ЕМГ А Ал) зростала у 1,3 та 2,0 раза відповідно.

Отримані дані свідчать, що на дні оз. Тельбін формується нестійка сукупність водоростей, яка складається переважно з видів, що потрапляють з інших біотопів. Аборигенні види представлені незначною кількістю, що дає підстави характеризувати таке угруповання як альгоагрегацію.

\section{Висновки}

У структурі мікрофітобентосу оз. Тельбін встановлено 7 еколого-морфологічних груп. Основу видового складу мікрофітобентосу формують планктонти, що осідають з товщі води на дно та перифітонти, принесені токами води з вищої водяної рослинності та твердих субстратів. Серед бентонтів найбільш суттєва роль у видовому багатстві належить ЕМГ БЕлд та ЕМГ Бкд.

Встановлені параметри відхилення відносних показників структурних компонентів мікрофітобентосу за різного ступеня антропогенного впливу. При його зростанні з 3 до 8 балів частка ЕМГ бентонтів у видовому багатстві знижується у 1,6-2 рази, а ЕМГ перифітонтів та ЕМГ планктонтів, навпаки, збільшується у 1,3-2 рази відповідно.

Нестійка сукупність водоростей, яка складається переважно з видів, які потрапляють на дно 3 інших біотопів, визначається як альгоагрегація, що вказує на несприятливі умови для розвитку резидентної альгофлори.

1. Баринова С. С., Медведева Л. А., Анисимова О. В. Биоразнообразие водорослей-индикаторов окружающей среды. Тель-Авив : Pilies Studio, 2006. 498 с.

2. Білоус О. П., Незбрицька І. М., Жежеря В. А. Вплив штучної аерації на екосистему озера Тельбін (Київ, Україна) на прикладі фітопланктону. Актуальні проблеми ботаніки та екології: матеріали міжнародної конференції молодих учених, Харків, 6-9 вер. 2019 р. Київ, 2019. С. 9.

3. Давидов О. А., Ларіонова Д. П. Еколого-морфологічні групи водоростей в мікрофітобентосі водного об'єкту лентичного типу урбанізованої території. Наук. зап. Терноп. нац. пед. ун-ту ім. Володимира Гнатюка. Сер.: Біол. 2013. №1 (54). С. 35-38.

4. Кондратьєва Н. В., Коваленко О. В., Приходькова Л. П. Визначник прісноводних водоростей Української РСР. І. Синьозелені водорості. К. : Наук. думка, 1984. Ч 1.388 с.

5. Методи гідроекологічних досліджень поверхневих вод / за ред. В. Д. Романенка. К. : ЛОГОС, 2006. $408 \mathrm{c}$.

6. Романенко О. В., Арсан О. М., Кіпніс Л. С., Ситник Ю. М. Екологічні проблеми київських водойм і прилеглих територій. К. : Наук. думка, 2015. 190 с.

7. Хільчевський В., Курило С. Гідролого-хімічна характеристика малих водойм міста Києва. Вісник Київського університету ім. Тараса Шевченка. 1999. № 5-6. С. 51-53.

8. Царенко П. М. Краткий определить хлорококковых водоростей Украинской ССР. Киев : Наук. думка, 1990. 208 с.

9. Топачевський О.В., Оксіюк О. П. Визначник прісноводних водоростей Української РСР. ХІ. Діатомові водорості. К. : Вид-во АН УРСР, 1960. $412 \mathrm{c.}$

10. Algae of Ukraine: diversity, nomenclature, taxonomy, ecology and geography / Ed. by P. M. Tsarenko, S. P. Wasser, E. Nevo. - Ruggell: Ganter Verlag, 2006-2011. (Vol. 1. Cyanoprokaryota, Euglenophyta, Chrysophyta, Xanthophyta, Raphidophyta, Phaeophyta, Dinophyta, Cryptophyta, Glaucocystophyta and Rhodophyta. 2006. 713 p.; Vol. 2. Bacillariophyta. 2009. 413 p.; Vol. 3. Chlorophyta. 2011. 511 p.).

11. Bukhtiyarova L. Diatoms of Ukraine. Inland waters. Kyiv : National Academy of Science of Ukraine, 1999. $133 \mathrm{p}$.

12. Guiry M. D., Guiry G. M. AlgaeBase. World-wide electronic publication, National University of Ireland, Galway, 2020. URL: http://www.algaebase.org (last accessed: 10.08.2020).

13. Klochenko P. D., Shevchenko T.F., Kharchenko G. V. Structural organization of phytoplankton and phytoepiphyton of the lakes of Kiev. Hydrobiol. Journal. 2013. Vol. 49, N 4. P. 47-63.

14. Krammer, Lange-Bertalot H. Bacillariophyceae. 1-4 Teile. In: Süsswasserflora von Mitteleuropa. 2/1 - 4. Stuttgart, Jena: VEB Gustav Fisher Verlag, 1986 - 1991. 876; 596; 576; 437 S.

15. Oksiyuk O. P., Davydov O. A. Algae cenoses of microphytobenthos in the Dnieper Reservoirs and in the Dnieper-Bug estuarine region. Hydrobiol. Journal. 2010. Vol. 46, N 4. P. 45-66.

16. Oksiyuk O. P., Davydov O. A. Approaches to the use of microphytobenthos to estimate the ecological status of water bodies are presented. It is suggested that the taxonomic and ecomorphological structure and 
quantitative parameters of microphytobenthos communities are feasible to use for ecological assessment of water bodies. Hydrobiol. Journal. 2006. Vol. 42, N 4. P. 93-106.

17. Oksiyuk O.P., Davydov O. A., Karpezo Yu. I. Ecological and Morphological Structure of Microphytobenthos. Hydrobiol. Journal. 2009. Vol. 45, N 2. P. 13-23.

\section{References}

1. Barinova S. S., Medvedeva L. A., Anisimova O. V. Bioraznoobrazie vodoroslej-indikatorov okruzhajushhej sredy. Tel'-Aviv: Pilies Studio, 2006. 498 s. [in Russian]

2. Bilous O. P., Nezbrytska I. M., Zhezheria V. A. Vplyv shtuchnoi aeratsii na ekosystemu ozera Telbin (Kyiv, Ukraina) na prykladi fitoplanktonu. Aktualni problemy botaniky ta ekolohii: materialy mizhnarodnoi konferentsii molodykh uchenykh., Kharkiv, 6-9 ver. 2019 r. Kyiv, 2019. S. 9. [in Russian]

3. Davydov O. A., Larionova D. P. Ekoloho-morfolohichni hrupy vodorostei v mikrofitobentosi vodnoho obiektu lentychnoho typu urbanizovanoi terytorii. Nauk. zap. Ternop. nats. ped. un-tu im. Volodymyra Hnatiuka. Ser.: Biol., 2013. №1 (54). S. 35-38. [in Ukrainian]

4. Kondratieva N. V., Kovalenko O. V., Prykhodkova L. P. Vyznachnyk prisnovodnykh vodorostei Ukrainskoi RSR. I. Synozeleni vodorosti, ch. 1. K. : Nauk. dumka, 1984. 388 s. [in Ukrainian]

5. Metody hidroekolohichnykh doslidzhen poverkhnevykh vod / za red. V. D. Romanenka. K. : LOHOS, 2006. 408 s. [in Ukrainian]

6. Romanenko O. V., Arsan O. M., Kipnis L. S., Sytnyk Yu. M. Ekolohichni problemy kyivskykh vodoim i prylehlykh terytorii. K. : Nauk. dumka, 2015. 190 s. [in Ukrainian]

7. Khilchevskyi V., Kurylo S. Hidroloho-khimichna kharakterystyka malykh vodoim micta Kyieva. Visnyk Kyivskoho universytetu im. Tarasa Shevchenka. 1999. № 5-6. S. 51-53. [in Ukrainian]

8. Carenko P. M. Kratkij opredelit' hlorokokkovyh vodorostej Ukrainskoj SSR. Kiev : Nauk. dumka, 1990. 208 s. [in Russian]

9. Topachevskyi O. V., Oksiiuk O.P. Vyznachnyk prisnovodnykh vodorostei Ukrainskoi RSR. KhI. Diatomovi vodorosti. K. : Vyd-vo AN URSR, 1960. 412 s. [in Ukrainian]

10. Algae of Ukraine: diversity, nomenclature, taxonomy, ecology and geography / Ed. by P.M. Tsarenko, S.P. Wasser, E. Nevo. - Ruggell: Ganter Verlag, 2006-2011. (Vol. 1. Cyanoprokaryota, Euglenophyta, Chrysophyta, Xanthophyta, Raphidophyta, Phaeophyta, Dinophyta, Cryptophyta, Glaucocystophyta and Rhodophyta. 2006. 713 p.; Vol. 2. Bacillariophyta. 2009. 413 p.; Vol. 3. Chlorophyta. 2011.511 p.).

11. Bukhtiyarova L. Diatoms of Ukraine. Inland waters / Bukhtiyarova L. - Kyiv : National Academy of Science of Ukraine, 1999. $133 \mathrm{p}$.

12. Guiry M. D., Guiry G. M. AlgaeBase. World-wide electronic publication, National University of Ireland, Galway, 2020. URL: http://www.algaebase.org (last accessed: 10.08.2020).

13. Klochenko P. D., Shevchenko T.F., Kharchenko G. V. Structural organization of phytoplankton and phytoepiphyton of the lakes of Kiev. Hydrobiol. Journal. 2013. V. 49, N 4. P. 47-63.

14. Krammer Bacillariophyceae. 1 - 4 Teile. - In: Süsswasserflora von Mitteleuropa / Krammer, LangeBertalot H. - 2/1 - 4. - Stuttgart, Jena: VEB Gustav Fisher Verlag, 1986-1991. 876; 596; 576; 437 S.

15. Oksiyuk O. P., Davydov O. A. Algae cenoses of microphytobenthos in the Dnieper Reservoirs and in the Dnieper-Bug estuarine region. Hydrobiol. Journal. 2010. V. 46, N 4. P. 45-66.

16. Oksiyuk O. P., Davydov O. A. Principles of methods for the assessment of the ecological status of water bodies using microphytobenthos. Hydrobiol. Journal. 2006. V. 42, N 4. P. 93-106.

17. Oksiyuk O.P., Davydov O. A., Karpezo Yu. I. Ecological and Morphological Structure of Microphytobenthos. Hydrobiol. Journal. 2009. V. 45, N 2. P. 13-23.

\section{O. A. Davydov, O. V. Kravtsova}

Institute of Hydrobiology of the NASU, Ukraine

\section{ECOLOGICAL-MORPHOLOGICAL STRUCTURE OF MICROPHYTOBENTHOS} IN TELBIN LAKE

The paper considers the findings of studies on ecological-morphological structure of microphytobenthos in Telbin Lake located in the residential community of Kyiv city.

The research study aimed to distinguish ecological-morphological groups of algae in microphytobenthos of the human-impacted waterbody within the urban area and to evaluate the role of microphytobenthos structural components in forming a certain type of algal community.

Microphytobenthos was sampled with the MB-TE microbenthometer within the littoral area at aquatic-vegetation-free sites and within the deep-water area of the lake. 
Algae sampling and laboratory processing of samples were performed in accordance with the methods generally accepted in hydrobiology. For diatoms identification permanent slides were made with special high-resolution mounting media. Ecological-morphological groups of benthic algae were distinguished considering the habitats of algae. The relative share in the microphytobenthos species richness was calculated for each group.

The degree of human impact on the lake ecosystem was evaluated according to the proven method, consisting in distinguishing the total number of factors, which most frequently affect the lake ecosystem.

The findings of studies on the ecological-morphological structure of microphytobenthos in Telbin Lake have made it possible to distinguish 7 ecological-morphological groups of algae. The species richness is mainly formed by periphytont and plankton, and benthonts are for the most part represented by the ecological-morphological group of eurytopic littoral diatoms. In the high-degree human impact waterbody ( 8 points) the share of benthonts' major ecological-morphological groups in the species richness decreases in 1.6-2 times, and the shares of periphyton and plankton increase 1.32 -fold respectively, as compared with low-degree human impact waterbody (3 points).

The resulting unstable algal community consisting mainly of species getting to the lake bottom from other habitats is defined as algal aggregation, which is indicative of unfavorable conditions for residential algal flora development.

Various waterbodies of Ukraine can differ significantly in the environmental variables playing a determining role in microphytobenthos structure and abundance.

Microphytobenthos may act as a reliable biological indicator of aquatic ecosystem's disturbance caused by human pressure upon waterbodies, responding to such pressure with the transformation of its structural elements.

For several waterbodies of Ukraine detailed analysis of microphytobenthos ecologicalmorphological structure made it possible to characterize bottom algal communities and to distinguish algal cenoses, which allowed to assess ecological state deterioration in different areas of the waterbodies under study.

The information on the microphytobenthos structural components of urban lakes is scarce.

Therefore, studying the ecological-morphological structure of microphytobenthos in various waterbodies within Kyiv city is of high importance.

Key words: microphytobenthos, ecological-morphological structure, algal ecology, algal communities, urban area waterbody.

Надійшла 13.10.2020.

УДК [581.526.2:581.526.3](282.243.7.05)

doi: $10.25128 / 2078-2357.20 .3-4.11$

\section{М. С. ПОГОРЕЛОВА}

Інститут гідробіології НАН України

просп. Героїв Сталінграда, 12, Київ, 04210

e-mail: chertkovams1988@gmail.com

\section{ПРОЯВ КРАЙОВОГО ЕФЕКТУ В СТРУКТУРІ ЗАРОСТЕЙ МАКРОФІТІВ ПРИ ЗМІНІ ГІДРОЛОГІЧНОГО РЕЖИМУ}

У роботі розглянуто зміни структурних характеристик та видового різноманіття макрофітів Кілійської дельти Дунаю при зміні екологічних умов як прояв крайового ефекту. Встановлено, що крайовий ефект достовірно проявляється при переході від лотичних умов (рукави дельти) до лентичних (непроточної водойми-кути). Показано, що в каналах, які з'єднують ці водотоки та водойми, формуються угруповання макрофітів 3 найбільшим видовим різноманіттям. У 